\title{
The preparedness of medical students from the Middle East for the modern curriculum: a cross-sectional study
}

\author{
F Rashid-Doubell, TP Doubell, R O’Sullivan, K Elmusharaf
}

RCSI-Bahrain, PO Box 15503, Adliya, Bahrain

\begin{abstract}
:
Aim

This study aims to examine whether there were any differences in self-directed learning readiness (SDLR) between students who entered medicine with a local Bahraini schools certificate and those students who entered with an international schools certificate.

Results

We analysed how self-management, desire for learning, self-control and total SDLR scores varied in relation to the student's previous exit award: 'A' levels (or equivalent) or Bahrain Secondary School (BSS) certificate. BSS certificate students had a significantly lower mean standardised desire for learning score (63.5) compared to those 'A' levels or equivalent (73.6; $\mathrm{p}=0.003$ ). BSS certificate students also had a significantly lower mean total self-directed learning readiness score (192.3) compared to those with the ' $\mathrm{A}$ ' levels and equivalent (214.5; $\mathrm{p}=0.015)$. When we controlled for all the other factors, secondary school award certificate was the only independent predictor of self-control (standardised beta $0.4 ; \mathrm{p}=0.02$ ) and SDLR (standardised beta 0.36; $\mathrm{p}=0.043$ ).

Conclusion

Self-directed learning is a key skill in the modern curriculum. Students who exit with a local Middle Eastern secondary school certificate are finding it difficult to prepare themselves for independent learning in medical school. This poses a challenge for institutions bringing a more active-learning type of curriculum to the Middle East.
\end{abstract}

Keywords: Self-directed learning; self-control; desire for learning; self-management; individualism; collectivism

\section{Introduction}

Promoting life-long learning amongst health professionals has been the main aim of a radical shake-up of medical education (Jackson \& Calman, 2006). Students have moved from the memorisation of facts to problem-solving and self-directed study, two skills found to be necessary for the practice of medicine (Barrows, 1983). Modern medical curricula have transformed from being delivered using a passive, didactic teaching approach to a more student-centred, active, self-directed learning one (Shin, Haynes et al., 1993). The importance of self-directed learning cannot be overstated; some authors have gone so far as suggesting that neglecting the development of a selfdirected learning is considered a serious disadvantage for the student learner (Kek \& Huijser, 2009). Part of this life-long learning process involves the need for students to adopt self-directed learning readiness often described as the process of deciding what to learn, and to what depth and breadth (Candy, 1991). Others have defined the concept of learning readiness as the degree to which the individual possesses the attitudes, abilities and traits necessary for self-directed learning (Wiley, 1983). When it comes to self-directed learning readiness, one thing that is widely agreed upon is the need for more research to explore how culture impacts on self-directed learning readiness in students outside of North America and Europe in this world of globalised medical education (Gukas, 2007). 
The globalisation of medical education has been rapid and intensive with very few medical schools escaping the effect (Jippes \& Majoor, 2011). But only a handful of studies have gone on to explore the cultural impact on the preparedness of students for self-directed learning from a cross-cultural perspective, Ahmad and Majid's appraisal was one such study, which showed that culture can strongly influence the development of self-directed learning readiness (Ahmad \& Majid, 2010). A second study reporting how culture challenges self-directed learning concluded that uncertainty, tradition and hierarchy impacted on self-directed learning, thus impeding the uptake of the new learning approach (Frambach, Driessen, et al., 2012).

Cultural identity can be broadly categorised as either collectivist or individualist. The main difference between collectivist and individualist cultures is the relative importance each places on the goals of the individual compared to the goals of the group (Braman, 1998). Children from collectivist cultures such as those living in the Middle East are situated in an environment which resolves around obedience, reliability, duty, cleanliness and order (Triandis, 2004). Taking charge of their own learning poses a major challenge to the majority of students entering tertiary education in the Arabian Gulf region (Al-Saadi, 2011a). Grow, 1991 observes that educational practices in public school and universities, does more to perpetuate dependency than to create self-direction (Grow, 1991). This practice is further emphasised by a recent report describing the "spoon-feeding learning model" practiced by students and teachers in Oman (Al-Saadi, 2011b). Al-Saadi argues that learning becomes more effective when learners are in control of their learning and aware of the learning process and of themselves as learners.

The objective of the study was to examine whether there were any differences in selfdirected readiness amongst students who entered medicine with a local Bahraini schools certificate and those students who entered with an international schools certificate. This study forms part of a larger ongoing study which introduced an intervention to enhance self-directed learning readiness (SDLR) in students regardless of their educational backgrounds.

\section{Methods}

\section{Setting}

Our study was conducted on the Bahrain campus of the Royal College of Surgeons in Ireland (RCSI-Bahrain) in Bahrain; an international university which delivers an Irish five-year undergraduate medical curriculum to students from all over the world with local Bahraini students making $40 \%$ of the overall cohort. The students varied in their ethnic background and their approaches to learning, amongst other things.

In the first year the cohort was composed of three distinct groups of students. The first group consisted of those who have directly entered the programme by either having appropriate 'A' level qualifications or equivalent (International Baccalaureate or High School Diploma). The second group was composed of students entering through a Foundation Year with a Bahrain Secondary School (BSS) certificate. The third group consisted of those students who already had a university degree.

\section{Study design}

In a cross-sectional study, we explored self-directed readiness amongst our first year medical students before they had undertaken any proper classes at the institution. Ethical permission was sought and obtained from the RCSI-Bahrain Research Ethics 
Committee. In the first week, of the first semester, students were given a brief overview of the study and invited to participate and if they agreed, written consent was obtained. Paper copies of the self-evaluation tool were then distributed to student who had consented, and they were asked to complete the questionnaire.

\section{Participants}

All 150 students' first year medical students in semester one were invited to participate in the study. From the first year cohort 65 students responded and completed the questionnaire (response rate 43\%). The inclusion criterion was set to include those students with a BSSC or 'A' levels or equivalent who directly entered the programme or who came through the Foundation Year (50 students were included). Students who were excluded from the study were those entering the programme that possessed a Higher Education exit award or repeating students (15 students were excluded).

\section{Tool}

The learning readiness of undergraduate medical students was determined using a scale originally devised by Fisher and his colleagues (Fisher, King, \& Tague, 2001) and later used to assess learning readiness amongst physiology students (Abraham et al., 2011). The SDLR questionnaire is a self-evaluation tool determining the SDLR of an individual student. Our questionnaire was a modification of one previously used by Fisher with nursing students (Fisher et al., 2001). The questionnaire was divided into three subcategories namely: self-management (9 items); desire for learning (13 items); self-control (11 items), giving a total of 33 items. Students were requested to respond to each item on a Likert scale (where 5=always, 4=often, 3=sometimes, 2=seldom, $1=$ never). The scale gave us the opportunity to calculate their subcategory scores as well as their total self-directed learning readiness. All items were scored in a forward manner and no reverse manner questions were posed.

The validity of the modified questionnaire was determined by content validity (exploring pertinent literature) and face validity (experts' opinion on the modified questionnaire). The reliability of the internal consistency was determined by calculating Cronbach's alpha for self-management (0.7), desire for learning (0.8) and self-control (0.76) as well as the overall value for self-directed learning readiness (0.9).

\section{Data management}

We calculated the total for each subcategory (self-management, desire for learning and self-control) by adding the scores of each item in that subcategory. The total scores were then standardized out of 100 by dividing the total score by the maximum score possible in that subcategory and multiplying by one hundred. For example, in the self-management scale there are 9 items with each item having a maximum score of 5 and so the student score was divided by 45 and multiplied by one 100 to provide a standardized subcategory score out of a 100 . The three subcategory scores were then added together to produce the standardized self-directed learning readiness total out of three hundred.

\section{Statistical analysis}

The data obtained from the questionnaire were entered, cleaned and prepared for analysis using IBM SPSS Statistics for Windows (IBM Corp., Armonk, NY, USA); 
data were summarised and presented using appropriate statistics: mean (standard deviation) and frequency (percentage) for normal-like and categorical variables respectively. Differences of SDLR and its three subcategories (self-management, desire for learning and self-control) in relation to students' characteristics were compared using independent student's t-test and 95\% confidence intervals (95\% CI) for the means. All statistical tests were two-sided. A Type I error rate of $p \leq 0.05$ was used for statistical significance. Furthermore, to address our primary research question, a multivariate regression analysis was performed to see the net effects of each of the students' characteristics (independent variables) in explaining variation in SDLR and its three subcategories.

\section{Results and Discussion}

\section{Participants' characteristics}

The majority of the participants were female (66\%). The predominant age group of students was less than 20 years (56\%). The students that left school with a Bahrain Secondary School Certificate comprised $28 \%$ of the respondents. Those entering from the RCSI-Bahrain Foundation Year course made up the largest proportion of students entering the Junior Cycle (58\%). The majority of the students were residents of the Middle East (86\%) and the remainders were residents in Asia. Table 1 summarises the general characteristics of the participants.

\section{Descriptive statistics}

Analysis of data revealed larger differences between the maximum and minimum values for each subcategory, self-management (35.5, 88.9), desire for learning (40, 90.77), self-control $(43.6,90.9)$ and the overall SDLR $(126.9,260.8)$. However, the mean scores (SD) for self-management was 68.6 (11.4), for desire for learning was 70.8 (11.2), for self-control was 68.9 (10.7), and for self-directed learning readiness was 208.3 (29.4). The descriptive statistics of the subcategories and the total SDLR are shown in Table 2.

\section{Determinants of SDLR}

The univariate results are shown in Table 3, indicating the mean difference between the two groups with $95 \%$ confidence interval as well as the p value.

When the total SDLR scores and its three subcategories were compared among different age groups there was little difference between those students who were less than 20-years-old and those who were older. Country of residence also had no impact on any of the three subcategories and neither did type of entry into the Junior Cycle.

Where there was a statistically significant difference it was between male and females students desire for learning, with male students having a higher desire for learning score (75.6) than females (68.3) (95\% CI of the Difference: 0.8 to 13.7, p value: 0.029).

The largest difference was found between students who had entered with a local Bahrain Secondary School Certificate and those students who were admitted with 'A' levels or an equivalent such as an IB or High School Diploma.

Students with IB and 'A' levels tend to have more desire for learning (73.6) compare to students with BSSC (63.5) (95\% CI of the Difference -16.6 to -3.6, P value 0.003). 
They also tend to have more self-control (71.2) compare to students with BSSC (63.1) (95\% CI of the Difference -15.8 to -0.4 , p value 0.04 )

The differences between the total SDLR scores amongst these two groups were also significantly higher among Students with IB and 'A' levels (214.5) than students with BSSC (192.3) (95\% CI of the Difference -39.8 to -4.5 , p value $=0.015)$

\section{Predicting factors which affect SDLR}

Table 4 shows the multivariate regression analysis which allowed us to see the net effects of each of the students' characteristics (independent variables) in explaining variation in SDLR and its three subcategories. When we controlled for all other factors, secondary school award certificate was the only independent predictor of the self-control (Standardized beta 0.4, $\mathrm{p}=0.02$ ) and SDLR (Standardized beta 0.36, $\mathrm{p}$ value $=0.043)$.

This study set out to examine whether there were any differences in SDLR amongst students who entered medicine from the local Bahraini schools and those students who exited schools with ' $A$ ' levels or equivalent awards. We found that there were indeed statistically significant differences between these students especially in the desire for learning and self-control categories. Our results plainly indicate that students who have exited from a local school with a secondary school certificate are not prepared in any of the any subdomains of self-learning readiness, selfmanagement; desire for learning; self-control, with the last two being statistically significant.

When exploring the literature for reasons to explain this difference between the two groups, one obvious factor jumps out, culture. Culture has been shown to play an important role in adult learning (Brookfield, 1980). Our local students are nurtured in a collectivist culture where the emphasis is on social harmony. This cultural influence does not encourage the development of traits such as motivation and readiness to accept responsibility essential for the successful self-directed learner (Garrison, 1992). A study done on Malaysian students, another good example of a collectivist culture, identified that Malaysian students struggle with the development of SDLR (Ahmad \& Majid, 2010). A conflict often arises in the minds of such students in adhering to their cultural values while attempting to promote their learning by developing their individualism, which is described much more explicitly by Knowles as 'a process in which the individual takes the initiative, with or without the help of others' (Knowles, 1975).

A possible second explanation why students from the local schools are struggling with SDLR could be the passive learning process adopted in most regional secondary schools. This type of passive learning was described in a study conducted at a Nepalese medical school where rote learning and reproduction of factual information predominated in their local schools (Shankar et al., 2011). In the Middle East, it was reported that spoon-feeding was prevalent in local schools in Oman, with pupils having no say on what to study and how to study it, and skills such as metacognition and reflection being largely excluded from the curriculum (Al-Saadi, 2011a). In an unpublished article Al-Saadi also concluded that taking charge of their own learning posed a major challenge for the majority of students entering tertiary education in the Arabian Gulf region [15]. This is reflected in our own findings where we show a statistically significant difference between the SDLR subgroup self-control local 
school students scoring who scored 63.1 out 100 and those taught using the British school system with the 'A' levels who scored 71.2 out of 100 , p value 0.04 .

The limitations of the study were that the data were collected on a self-reporting basis which could be subject to recall bias. Additionally, the small unequal sample size among the two groups could have contributed to some of the observed differences.

Integrating unprepared students into modern Western medical curricula remains an interesting challenge for those of us engaged in teaching. Whilst students struggle to adopt individualistic traits in order cope with modern learning, teachers working in international medical schools have to devise strategies to expedite the transition of local students into their Western curricula, with the emphasis squarely placed on SDLR as a learning strategy for formal undergraduate studies and beyond into for life-long learning.

\section{Figures and Tables}

Table 1: General characteristics of the participants

\begin{tabular}{|c|c|c|c|}
\hline Main group & Sub-group & Frequency & Percent \\
\hline \multirow[t]{2}{*}{ Age groups } & $<20$ years & 28 & 56 \\
\hline & 20 years or more & 22 & 44 \\
\hline \multirow[t]{2}{*}{ Gender } & Male & 17 & 34 \\
\hline & Female & 33 & 66 \\
\hline \multirow[t]{2}{*}{ Secondary school award } & Bahrain Secondary School Certificate & 14 & 28 \\
\hline & IB and A levels & 36 & 72 \\
\hline \multirow[t]{2}{*}{ Country of residence of student } & Middle Eastern & 43 & 86 \\
\hline & Asian & 7 & 14 \\
\hline \multirow[t]{2}{*}{ Type of entry in to Junior Cycle } & Foundation Year & 29 & 58 \\
\hline & Direct Entry & 21 & 42 \\
\hline
\end{tabular}

Table 2: Descriptive statistics of the three subcategories and combined SDLR score of the participants

\begin{tabular}{|l|l|l|l|l|}
\hline Statistics & Self-management & Desire for learning & Self-control & SDLR \\
\hline Mean & 68.6 & 70.8 & 68.9 & 208.3 \\
\hline Std. Error of Mean & 1.6 & 1.6 & 1.5 & 4.2 \\
\hline Median & 71.1 & 72.3 & 70 & 207.7 \\
\hline Std. Deviation & 11.4 & 11.2 & 10.7 & 29.4 \\
\hline Minimum & 35.6 & 40 & 43.6 & 126.9 \\
\hline Maximum & 88.9 & 90.77 & 90.9 & 260.8 \\
\hline
\end{tabular}


Table 3: Mean differences between the two groups of participants

\begin{tabular}{|c|c|c|c|c|c|}
\hline & & $\mathrm{SM}$ & DFL & SC & SDL \\
\hline \multirow[t]{5}{*}{ Age groups } & $<20$ years & 68.4 & 73.1 & 68.3 & 209.8 \\
\hline & 20 years or more & 68.8 & 67.9 & 69.8 & 206.4 \\
\hline & Mean Difference & -0.4 & 5.2 & -1.4 & 3.4 \\
\hline & $\begin{array}{l}95 \% \text { CI of the } \\
\text { Difference }\end{array}$ & -7 to 6.2 & $\begin{array}{rr}-1.1 & \text { to } \\
11.5 & \\
\end{array}$ & $\begin{array}{ll}-7.6 & \text { to } \\
4.8 & \\
\end{array}$ & $\begin{array}{ll}-13.6 & \text { to } \\
20.3 & \\
\end{array}$ \\
\hline & $\mathrm{P}$ value & 0.91 & 0.1 & 0.64 & 0.69 \\
\hline
\end{tabular}

\begin{tabular}{|l|l|l|l|l|l|}
\hline \multirow{5}{*}{ Gender } & Male & 69.5 & 75.6 & 70.5 & 215.6 \\
\cline { 2 - 7 } & Female & 68.1 & 68.3 & 68.2 & 204.6 \\
\hline & Mean Difference & 1.5 & 7.2 & 2.3 & 11.0 \\
\hline & $\begin{array}{l}95 \% \text { CI of the } \\
\text { Difference }\end{array}$ & $\begin{array}{l}-5.5 \\
8.4\end{array}$ & 0.8 to 13.7 & $\begin{array}{l}-4.2 \\
8.8\end{array}$ & $\begin{array}{c}-6.5 \\
28.5\end{array}$ \\
\hline & P value & 0.673 & 0.029 & 0.474 & 0.213 \\
\hline
\end{tabular}

\begin{tabular}{|l|l|l|l|l|l|}
\hline \multirow{5}{*}{ Secondary school award } & BSSC & 65.7 & 63.5 & 63.1 & 192.3 \\
\cline { 2 - 6 } & IB and A levels & 69.7 & 73.6 & 71.2 & 214.5 \\
\hline & Mean Difference & -4.0 & -10.1 & -8.1 & -22.2 \\
\hline & $\begin{array}{l}95 \% \text { CI of the } \\
\text { Difference }\end{array}$ & $\begin{array}{l}3.2 \\
\text { If to }\end{array}$ & $\begin{array}{l}-16.6 \text { to }- \\
3.6\end{array}$ & $\begin{array}{l}-15.8 \text { to }- \\
0.4\end{array}$ & $\begin{array}{l}-39.8 \\
4.5\end{array}$ \\
\hline & P value & 0.27 & 0.003 & 0.04 & 0.015 \\
\hline
\end{tabular}

\begin{tabular}{|c|c|c|c|c|c|}
\hline \multirow{5}{*}{$\begin{array}{l}\text { Country of residence of } \\
\text { student }\end{array}$} & Middle Eastern & 68.6 & 71.0 & 69.0 & 208.7 \\
\hline & Asian & 68.3 & 69.5 & 68.6 & 206.3 \\
\hline & Mean Difference & 0.4 & 1.6 & 0.4 & 2.4 \\
\hline & $\begin{array}{l}95 \% \text { CI of the } \\
\text { Difference }\end{array}$ & $\begin{array}{ll}-9.1 & \text { to } \\
9.8 & \end{array}$ & $\begin{array}{ll}-7.7 & \text { to } \\
10.8 & \\
\end{array}$ & $\begin{array}{l}-8.5 \text { to } \\
9.3\end{array}$ & $\begin{array}{cc}-22 & \text { to } \\
26.7 & \\
\end{array}$ \\
\hline & $\mathrm{P}$ value & 0.94 & 0.73 & 0.92 & 0.85 \\
\hline
\end{tabular}

\begin{tabular}{|l|l|l|l|l|l|}
\hline \multirow{3}{*}{$\begin{array}{l}\text { Type of entry in to Junior } \\
\text { Cycle }\end{array}$} & Foundation Year & 69.5 & 68.4 & 67.8 & 205.7 \\
\cline { 2 - 6 } & Direct Entry & 67.3 & 74.1 & 70.6 & 212.0 \\
\cline { 2 - 6 } & $\begin{array}{l}\text { Mean Difference } \\
\text { M CI of the }\end{array}$ & $\begin{array}{l}-4.4 \text { to } \\
8.8\end{array}$ & -12 to 0.5 & -9 to 3.4 & -23.3 \\
\cline { 2 - 6 } & $\begin{array}{l}\text { 95\% to } \\
\text { Difference }\end{array}$ & 0.51 & 0.071 & 0.37 & 0.46 \\
\cline { 2 - 6 } & P value & & -2.8 & -6.3 \\
\hline
\end{tabular}


Table 4: Results of Multivariate Regression Analysis

\begin{tabular}{|c|c|c|c|c|c|c|c|c|}
\hline & \multicolumn{2}{|l|}{ SM } & \multicolumn{2}{|l|}{ DFL } & \multicolumn{2}{|l|}{$\mathrm{SC}$} & \multicolumn{2}{|l|}{ SDL } \\
\hline & Beta & $\begin{array}{l}\mathrm{P} \\
\text { value }\end{array}$ & Beta & $\begin{array}{l}\mathrm{P} \\
\text { value }\end{array}$ & Beta & $\begin{array}{l}\mathrm{P} \\
\text { value }\end{array}$ & Beta & $\begin{array}{l}\mathrm{P} \\
\text { value }\end{array}$ \\
\hline Age groups & -0.06 & 0.77 & -0.06 & 0.737 & 0.33 & 0.087 & 0.07 & 0.707 \\
\hline Gender & 0.00 & 0.987 & -0.15 & 0.331 & 0.05 & 0.732 & -0.04 & 0.820 \\
\hline Secondary school award & 0.25 & 0.171 & 0.30 & 0.07 & 0.40 & 0.02 & 0.36 & 0.043 \\
\hline Country of residence & -0.02 & 0.873 & -0.02 & 0.874 & -0.07 & 0.629 & -0.04 & 0.769 \\
\hline $\begin{array}{l}\text { Type of entry in to Junior } \\
\text { Cycle }\end{array}$ & -0.25 & 0.24 & 0.04 & 0.828 & 0.18 & 0.353 & -0.01 & 0.946 \\
\hline Constant & $\begin{array}{l}69.4 \\
5\end{array}$ & 0 & 65.89 & 0.000 & 39.43 & 0.017 & 174.77 & 0.000 \\
\hline R Square & $\begin{array}{l}0.06 \\
2\end{array}$ & & 0.198 & & 0.178 & & 0.125 & \\
\hline
\end{tabular}

\section{Conclusions}

Self-directed learning is a key skill in the modern medical curriculum. Students who exit with a local secondary school certificate seem unprepared for this type of new learning strategy. This creates an educational challenge for institutions bringing a more active-learning modern curriculum to the Middle East. Consideration must therefore be given to the development of appropriate mechanisms to assist such students in adopting this style of learning.

Some recommendations include:

1. To realign the secondary school curriculum in order to adjust for the mismatch between secondary and tertiary education

2. Make an adaptation to introduce skills in the preparatory year at the tertiary degree level to enhance the transition

3. An opportunity is created for private sector to produce short courses to help bridge the gap for autonomous students

Any future research should focus on the two key areas to enhance the transition for students from secondary to tertiary education.

1. Identify implementation challenges

2. Design innovative approaches

\section{References}

Abraham, R. R., Fisher, M., Kamath, A., Izzati, T. A., Nabila, S., \& Atikah, N. N. (2011). Exploring first-year undergraduate medical students' self-directed learning readiness to physiology. Advances in Physiology Education, 35(4), 393-395.

Ahmad, B. E., \& Majid, F. A. (2010). Self-directed Learning and Culture: A Study on Malay Adult Learners. Procedia-Social and Behavioral Sciences, 7, 254-263.

Al-Saadi, H. M. (2011a). From spoon-feeding to self feeding: helping learners take control of their own learning. Arab World English Journal, 2 (3), 95-114. 
Al-Saadi, H. M. (2011b). Towards a pedagogy for autonomy in language education in Oman. Retrieved from http://www.researchgate.net/profile/Hashil_Al-Saadi/publications

Barrows, H. S. (1983). Problem-based, self-directed learning. JAMA, 250(22), 3077-3080.

Braman, O. R. (1998). The cultural dimension of individualism and collectivism as a factor in adult self-directed learning readiness. (1998 Dissertation). Retrieved from http://aquila.usm.edu/theses_dissertations/1806

Brookfield, S. D. (1980). Independent adult learning. [electronic resource]: University of Leicester.

Candy, P. C. (1991). Self-direction for lifelong learning: a comprehensive guide to theory and practice. San Francisco: Jossey-Bass.

Fisher, M., King, J., \& Tague, G. (2001). Development of a self-directed learning readiness scale for nursing education. Nurse Education Today, 21(7), 516-525.

Frambach, J. M., Driessen, E. W., Chan, L.-C., \& van der Vleuten, C. P. M. (2012). Rethinking the globalisation of problem-based learning: how culture challenges selfdirected learning. Medical Education, 46(8), 738-747.

Garrison, D. R. (1992). Critical Thinking and Self-Directed Learning in Adult Education: An Analysis of Responsibility and Control Issues. Adult Education Quarterly, 42(3), 136148.

Grow, G. O. (1991). Teaching Learners To Be Self-Directed. Adult Education Quarterly, 41(3), 125-149.

Gukas, I. D. (2007). Global paradigm shift in medical education: issues of concern for Africa. Med Teach, 29(9), 887-892.

Jackson, M., \& Calman, K. (2006). Medical Education past, present and future. Medical Education, 40(3), 190-192.

Jippes, M., \& Majoor, G. D. (2011). Influence of national culture on the adoption of integrated medical curricula. Adv Health Sci Educ Theory Pract, 16(1), 5-16.

Kek, M. Y. C. A., \& Huijser, H. (2009). What makes a deep and self-directed learner: exploring factors that influence learning approaches and self-directed learning in a PBL context at a Malaysian private university. Proceedings of the 2nd International Problembased Learning Symposium (PBL 2009), 708-718.

Knowles, M. S. (1975). Self-directed Learning: A Guide for Learners and Teachers: Association Press.

Shankar, R., Bajracharya, O., Jha, N., Gurung, S. B., Ansari, S. R., \& Thapa, H. S. (2011). Change in medical students' readiness for self-directed learning after a partially problembased learning first year curriculum at the KIST medical college in Lalitpur, Nepal. Educ Health (Abingdon), 24(2), 552.

Shin, J. H., Haynes, R. B., \& Johnston, M. E. (1993). Effect of problem-based, self-directed undergraduate education on life-long learning. CMAJ, 148(6), 969-976.

Triandis, H. C. (2004). Culture and Social Behavior: McGraw Hill Custom Publishing.

Wiley, K. (1983). Effects of a self-directed learning project and preference for structure on self-directed learning readiness. Nurs Res, 32(3), 181-185. 